\title{
Evaluation of marginal discrepancy in metal frameworks fabricated by sintering-based computer-aided manufacturing methods
}

\author{
Necati Kaleli ${ }^{*}$, Çağrı Ural ${ }^{2}$, Yeşim Ölçer Us ${ }^{3}$ \\ 'Department of Dentistry Services, Vocational School of Health Services, Ondokuz Mayıs University, Samsun, Turkey \\ ${ }^{2}$ Department of Prosthodontics, Faculty of Dentistry, Ondokuz Mayıs University, Samsun, Turkey \\ ${ }^{3}$ Department of Prosthodontics, School of Dental Medicine, Bahçeşehir University, İstanbul, Turkey
}

\begin{abstract}
PURPOSE. The aim of this in vitro study was to evaluate the effect of sintering procedures on marginal discrepancies of fixed partial metal frameworks fabricated using different sintering-based computer-aided design and computer/aided manufacturing (CAD/CAM) techniques. MATERIALS AND METHODS. Forty resin die models of prepared premolar and molar abutment teeth were fabricated using a three-dimensional (3D) printer and divided into four groups $(\mathrm{n}=10)$ according to the fabrication method of metal frameworks used: HM (via hard milling), SM (via soft metal milling), L25 (via direct metal laser melting [DMLM] with a $25 \mu \mathrm{m}$ layer thickness), and L50 (via direct DMLM with a $50 \mu \mathrm{m}$ layer thickness). After the metal frameworks were fabricated and cemented, five vertical marginal discrepancy measurements were recorded in each site (i.e., buccal, facing the pontic, lingual, and facing away from the pontic) of both abutment teeth under a stereomicroscope $(\times 40)$. Data were statistically analyzed at a significance level of 0.05. RESULTS. No statistically significant differences $(P>.05)$ were found among the four axial sites of metal frameworks fabricated by sintering-based CAD/CAM techniques. The HM and L25 groups showed significantly $(P<.001)$ lower marginal discrepancy values than the SM and L50 groups. CONCLUSION. Marginal discrepancy in the sites facing the pontic was not influenced by the type of sintering procedure. All fabrication methods exhibited clinically acceptable results in terms of marginal discrepancies. [J Adv Prosthodont 2020;12:124-30]
\end{abstract}

KEYWORDS: Laser sintering; Metal framework; Marginal discrepancy; Soft metal milling

\section{INTRODUCTION}

Metal-ceramic restoration is a common prosthetic treatment option in dentistry. Although the ceramic part of a restoration is exposed to occlusal forces during chewing actions,

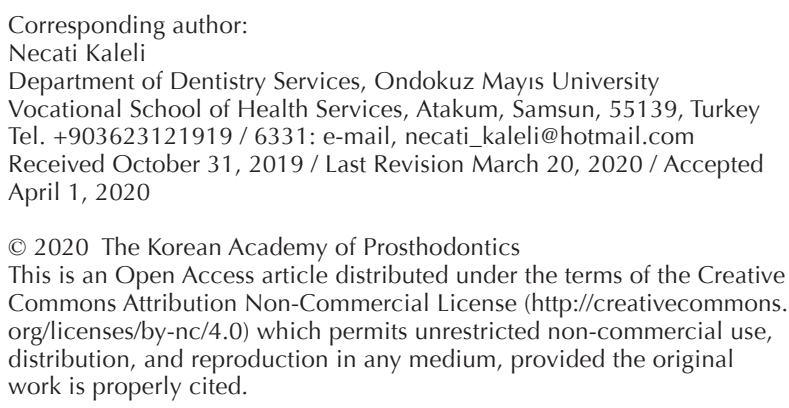

This work was financially supported by the Scientific and Technological Research Council of Turkey (grant number: 118S705). the restoration's clinical survival primarily depends on the metal framework's physical and mechanical properties ${ }^{1}$ and, to a greater extent, the accuracy of fit between the restoration and abutment tooth. ${ }^{2}$ The increase in marginal discrepancy results in cement dissolution, which eventually leads to plaque accumulation, secondary carries, and periodontal diseases. ${ }^{3-5}$ The conventional lost-wax method, which requires great technical accuracy during the casting process, has been used in the fabrication of metal-ceramic restorations for a long time. However, casting imperfections and the investment material's dimensional instability have a negative effect on the marginal adaptation of metal frameworks. ${ }^{2}$ Today, such problems caused by casting procedures can be overcome by the use of computer-aided design and computeraided manufacturing (CAD/CAM) systems in dental practice. ${ }^{2,6,7}$

In accordance with the preferences of dental laboratories, several CAD/CAM systems are used in the production 
of metal frameworks. ${ }^{8}$ Among these systems, laser sintering systems are among the most preferred technologies due to its advantages, such as reduced cost, short manufacturing times, and high level of accuracy. ${ }^{7,8}$ In laser sintering systems, powdered metal particles are sintered, layer-by-layer, in line with the CAD data until the fabrication is complete. Laser sintering systems currently used in dentistry operate on the principle of direct metal laser sintering (DMLS) or direct metal laser melting (DMLM). ${ }^{10}$ DMLS machines melt the metal powder partially, whereas DMLM machines melt it completely. ${ }^{11}$ The layer thickness used during the sintering process plays a significant role in metal framework fabrication. ${ }^{12,13}$ Increasing the layer thickness shortens the manufacturing time; however, this may lead to several problems, such as an irregular surface finish, weakened mechanical properties, and reduced accuracy. ${ }^{10,14-19}$

Milling systems were some of the first CAD/CAM methods developed. Metal frameworks manufactured by milling machines have a high level of structural homogeneity. ${ }^{2}$ However, the milling process of metal blocks takes too long, and the milling equipment wears out more quickly due to the hardness of base metal alloys. ${ }^{20,21}$ Because of these disadvantages, pre-sintered soft metal blocks were developed as an alternative to hard milling systems. Soft metal blocks are produced by compressing the metal powders with isostatic pressure. This prevents milling tools from rapid abrasions and decreases the manufacturing time and costs. Milled metal frameworks are sintered to reach full density, which is similar to the sintering process used for pre-sintered zirconia. ${ }^{22-25}$

The abutment teeth are connected to the pontic part in fixed partial restorations, and this part has more material content in terms of mass and volume than other parts of the metal framework. In the dental literature, some studies have reported that the marginal discrepancy in zirconia restorations increases in areas close to the pontic. ${ }^{26,27}$ All CAD/ CAM systems used in the fabrication of metal frameworks, except for hard milling, involve a sintering process. However, the effect of sintering procedures on marginal discrepancy in the sites facing the pontic is unclear. The main purpose of this study was to evaluate the effect of sintering procedures on marginal discrepancy of fixed partial metal frameworks fabricated using different sintering-based CAD/CAM methods. The hypothesis was that the degree of marginal discrepancy would increase at the pontic of metal frameworks fabricated using sintering-based CAD/CAM methods.

\section{MATERIALS AND METHODS}

A single bronze metal die model representing prepared premolar and molar teeth was created using a computer numerical control machine (Fig. 1). The die model was scanned using a laboratory scanner (E2, 3Shape, Copenhagen, Denmark), and 40 resin (E-Model, Envision'Tec, Dearborn, MI, USA) die models were fabricated using a three-dimensional (3D) printer (Vida, EnvisionTec, Dearborn, MI, USA). The resin die models were divided into 4 groups $(\mathrm{n}=$

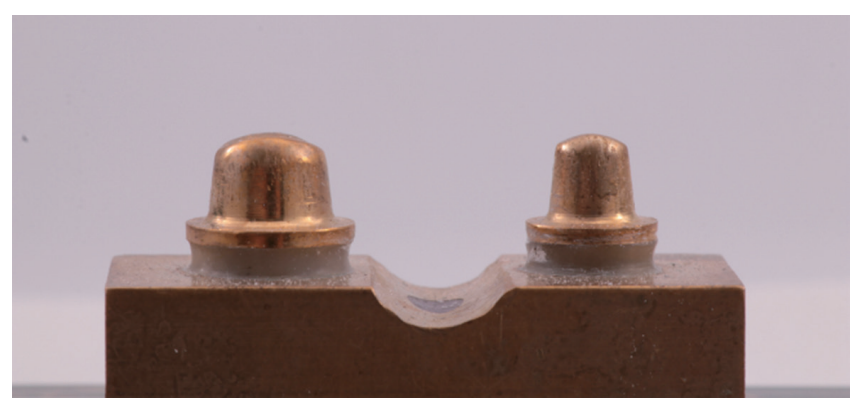

Fig. 1. Metal die model used in the study.

10) according to the methods used to fabricate the metal framework: hard metal milling (HM), soft metal milling (SM), DMLM with a $25 \mu \mathrm{m}$ layer thickness (L25), and DMLM with a $50 \mu \mathrm{m}$ layer thickness (L50). Each resin model was scanned using the same laboratory scanner, and the scan data were transferred to design software (exocad v2.2, exocad, Darmstadt, Germany). All the metal frameworks were designed to have a thickness of $0.5 \mathrm{~mm}$ in the abutment teeth and $6 \mathrm{~mm}^{2}$ in the connector area. The cement film's thickness was set as $30 \mu \mathrm{m}$.

In the HM group, the CAD data were transferred to a milling machine (Redon Hybrid, Redon, Istanbul, Turkey), and 10 three-unit metal frameworks were milled from cobalt-chromium (Co-Cr) hard blanks (Starbond CoS Disc Basic, S \& S Scheftner GmbH, Mainz, Germany). After the milling process was completed, metal frameworks were finished using tungsten carbide finishing burs. Milled metal frameworks were accepted as the control group because they did not undergo heat treatment.

In the SM group, the CAD data were transferred to a milling machine, and 10 three-unit metal frameworks were milled from pre-sintered Co-Cr soft metal blanks (CopraSintec K, Whitepeaks Dental Solutions GmbH, Hamminkeln, Germany). After the milling process was completed, all soft metal frameworks were sintered in an argon atmosphere for 3 hours at $1450^{\circ} \mathrm{C}$. After the sintering process was completed, all the metal frameworks were finished using tungsten carbide finishing burs.

In the L25 group, the CAD data were transferred to a DMLM machine (MLab Cusing 200R, Concept Laser GmbH, Lichtenfels, Germany), and 10 three-unit metal frameworks were laser sintered with a $25 \mu \mathrm{m}$ layer thickness from $\mathrm{Co}-\mathrm{Cr}$ metal powder (Remanium Star CL, Dentaurum GmbH, Ispringen, Germany). The manufacturing process was completed in 195 minutes. Thereafter, all the metal frameworks were annealed in a sintering furnace (Mikrotek, Mikrotek Dental, Ankara, Turkey) according to the manufacturer's instructions. After the annealing process was completed, all the metal frameworks were finished using tungsten carbide finishing burs.

In the L50 group, the CAD data were transferred to a DMLM machine, and 10 three-unit metal frameworks were 
laser sintered with a $50 \mu \mathrm{m}$ layer thickness from Co-Cr metal powder (Remanium Star CL, Dentaurum GmbH, Ispringen, Germany). The manufacturing process was completed in 160 minutes. Thereafter, all the metal frameworks were annealed in a sintering furnace (Mikrotek, Mikrotek Dental, Ankara, Turkey) according to the manufacturer's instructions. After the annealing process was completed, all the metal frameworks were finished using tungsten carbide finishing burs.

All metal frameworks were cemented to master resin models with a temporary cement agent (TempoCemNE, DMG, Hamburg, Germany) under a standard $200 \mathrm{~N}$ load using a dynamometer stand. The excessive cement remnants were removed from the marginal boundaries. To evaluate the samples' marginal discrepancies, a metal bolt was cemented to the bottom of the resin die models using a cyanoacrylate adhesive agent. The bolts were used to fix the die models to the screw passing through the measurement stand, which was fabricated using a parallelometer sub-tray, allowing the samples to rotate on 3 different axes (Fig. 2). The four corners (the ends of the lines that cross each other), at $0.5 \mathrm{~mm}$ below the marginal finish of each abutment tooth, were marked using an acetate pencil, and the area between two corners was determined to be an axial site. The marginal discrepancy measurements were recorded in four axial sites: buccal, facing the pontic, lingual, and facing away from the pontic.

Marginal discrepancy evaluations were conducted at a magnification of $\times 40$ using a stereomicroscope (SZX16, Olympus, Tokyo, Japan) equipped with a digital camera (DP73, Olympus, Tokyo, Japan), which were integrated into a measurement software (Stream Basic, Olympus Soft Imaging Solutions GmbH, Munster, Germany). Measurements were recorded vertically from the framework's margin to the marginal finish line. Five marginal discrepancy measurements, at equal intervals, were recorded at each axial site (Fig. 3). The arithmetic mean of five measurements was considered as the mean marginal discrepancy value of the axial site, and

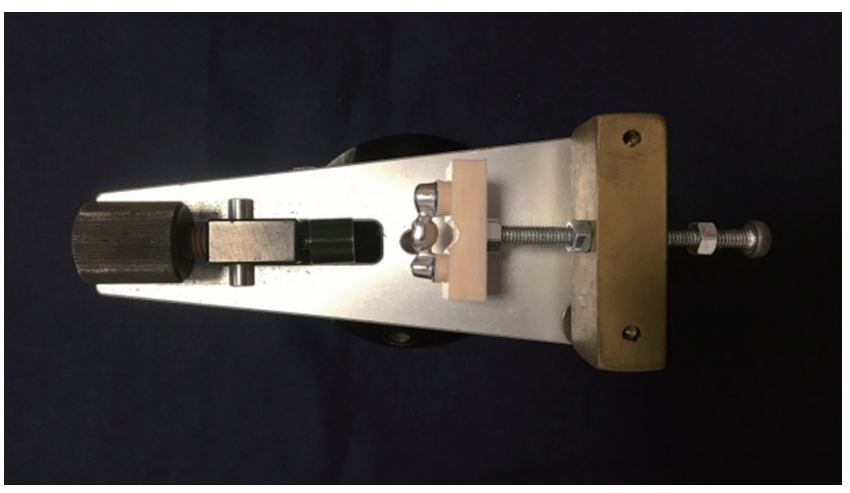

Fig. 2. The parallelometer sub-tray stand, which allows rotation of die models, used in marginal discrepancy measurements. the arithmetic mean of the four axial sites was considered as the mean marginal discrepancy value of the abutment tooth.

Data were statistically analyzed using a statistical software (IBM SPSS Statistics, v21.0, IBM Corp., Chicago, IL, USA). The distribution of the data was evaluated with a Shapiro Wilk test, and the data exhibited a normal distribution $(P>$ .05). Differences among the axial sites were evaluated using univariate analysis of variance (ANOVA), one-way ANOVA, and Tukey's multiple comparison tests, and differences among the fabrication methods were evaluated using oneway ANOVA and Tukey's honestly significant difference (HSD) tests at a significance level of 0.05 . Homogeneity was evaluated using the Levene's test.

\section{RESULTS}

In premolars, the univariate ANOVA test results revealed significant differences ( $\mathrm{df}=3 ; \mathrm{F}=2.991 ; P=.033$ ) among the axial sites. The one-way ANOVA results for each fabrication method were as follows: no significant differences were found among the axial sites in the $\mathrm{SM}(\mathrm{df}=3 ; \mathrm{F}=$ $0.269 ; P=0.847$ ), L25 ( $\mathrm{df}=3 ; \mathrm{F}=2.002 ; P=0.131$ ), or L50 ( $\mathrm{df}=3 ; \mathrm{F}=0.171 ; P=0.915$ ) groups, but significant differences were found among the axial sites in the HM (df $=3 ; \mathrm{F}=5.350 ; P=0.004$ ) group. However, multiple comparisons revealed that this difference resulted from the buccal site rather than the site facing the pontic. The mean marginal discrepancy values, standard deviations (SD), and multiple comparisons among the axial regions of premolars for each fabrication method are shown in Table 1.

In molars, univariate ANOVA test results showed no significant difference ( $\mathrm{df}=3 ; \mathrm{F}=1.044 ; P=0.375$ ) among the axial sites. The one-way ANOVA results for each fabrication method were as follows for the four groups: HM (df $=3 ; \mathrm{F}=0.459 ; P=0.713), \mathrm{SM}(\mathrm{df}=3 ; \mathrm{F}=2.365 ; P=$ 0.087 ), L25 ( $\mathrm{df}=3 ; \mathrm{F}=1.113 ; P=0.356$ ), and L50 ( $\mathrm{df}=3$; $\mathrm{F}=0.519 ; P=0.672)$. The mean marginal discrepancy values, standard deviations (SD), and multiple comparisons

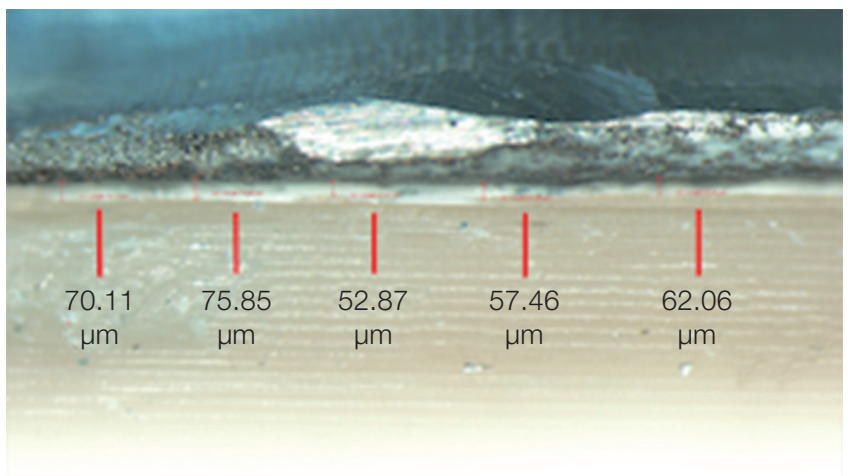

Fig. 3. Recorded marginal discrepancy measurements at equal intervals. 
Table 1. Mean marginal discrepancy values $(\mu \mathrm{m})$ and SD in axial sites of premolars

\begin{tabular}{lcccc}
\hline Fabrication method & HM & SM & L25 & L50 \\
Axial site & Mean (SD) & Mean (SD) & Mean (SD) & Mean (SD) \\
\hline Buccal & $50(7)^{\mathrm{a}}$ & $68(11)^{\mathrm{a}}$ & $54(7)^{\mathrm{a}}$ & $64(11)^{\mathrm{a}}$ \\
Facing the pontic & $61(8)^{\mathrm{b}}$ & $71(8)^{\mathrm{a}}$ & $60(9)^{\mathrm{a}}$ & $65(12)^{\mathrm{a}}$ \\
Lingual & $58(3)^{\mathrm{b}}$ & $69(7)^{\mathrm{a}}$ & $61(5)^{\mathrm{a}}$ & $67(10)^{\mathrm{a}}$ \\
Facingaway from the pontic & $55(4)^{\mathrm{ab}}$ & $67(7)^{\mathrm{a}}$ & $60(8)^{\mathrm{a}}$ & $65(7)^{\mathrm{a}}$ \\
\hline
\end{tabular}

*Values having same letter in a column are not significantly different $(P>.05)$.

Table 2. Mean marginal discrepancy values $(\mu \mathrm{m})$ and SD in axial sites of molars

\begin{tabular}{lcccc}
\hline $\begin{array}{l}\text { Fabrication method } \\
\text { Axial site }\end{array}$ & HM & SM & L25 & L50 \\
Mean (SD) & Mean (SD) & Mean (SD) & Mean (SD) \\
\hline Buccal & $60(8)^{\mathrm{a}}$ & $69(11)^{\mathrm{a}}$ & $55(10)^{\mathrm{a}}$ & $63(7)^{\mathrm{a}}$ \\
Facing the pontic & $60(7)^{\mathrm{a}}$ & $74(8)^{\mathrm{a}}$ & $57(5)^{\mathrm{a}}$ & $66(6)^{\mathrm{a}}$ \\
Lingual & $57(4)^{\mathrm{a}}$ & $69(4)^{\mathrm{a}}$ & $61(8)^{\mathrm{a}}$ & $66(7)^{\mathrm{a}}$ \\
Facingaway from the pontic & $59(6)^{\mathrm{a}}$ & $65(6)^{\mathrm{a}}$ & $60(10)^{\mathrm{a}}$ & $64(7)^{\mathrm{a}}$ \\
\hline
\end{tabular}

*Values having same letter in a column are not significantly different $(P>.05)$.

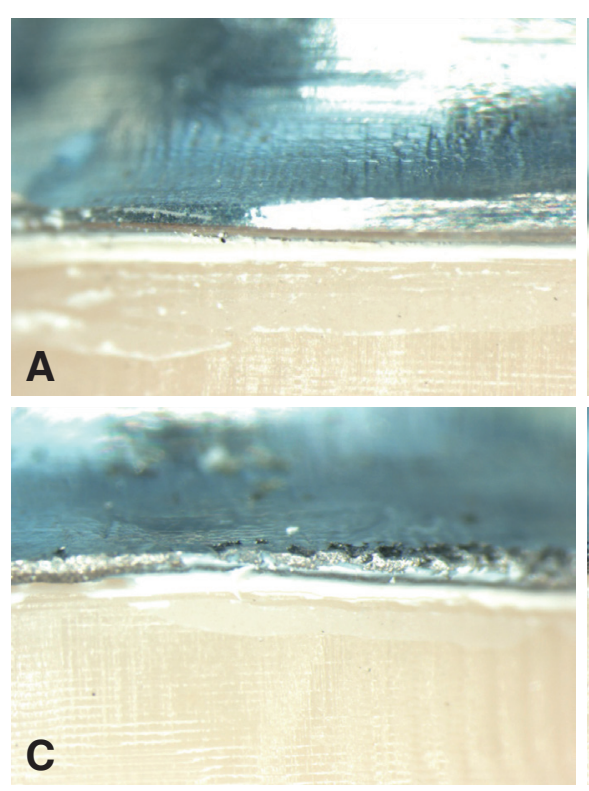

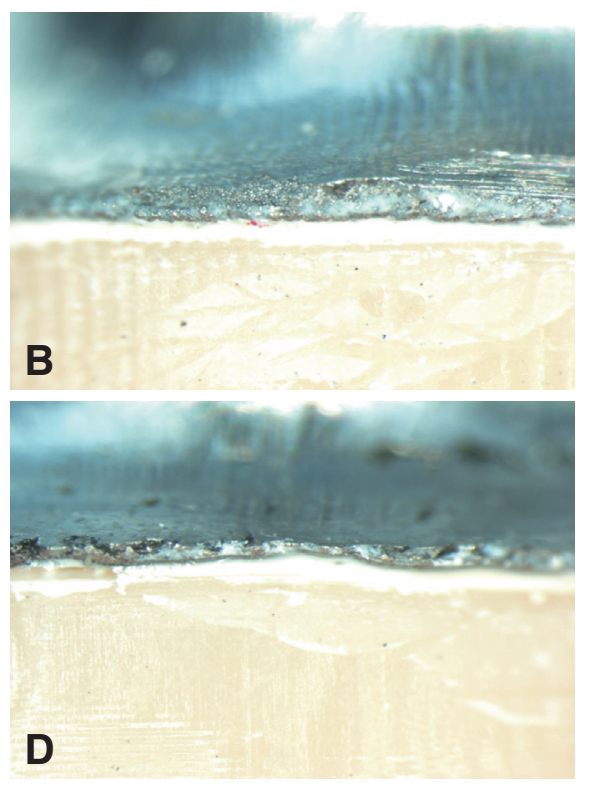

Fig. 4. Images taken $(\times 40)$ from each fabrication group. The differences in marginal integrity and discrepancies are presented: (A) Hard metal milling, (B) Soft metal milling, (C) Laser sintering with $25 \mu \mathrm{m}$ layer thickness, (D) Laser sintering with $50 \mu \mathrm{m}$ layer thickness. among the axial sites of molars for each fabrication method are shown in Table 2.

To evaluate differences among the fabrication methods, the data recorded for both premolars and molars were combined. The one-way ANOVA results revealed that there was a significant difference $(\mathrm{df}=3 ; \mathrm{F}=16.771 ; P<.001)$ among the fabrication methods (Fig. 4). The HM and L25 groups exhibited significantly lower marginal discrepancy values than the SM and L50 groups $(P<.05)$. The mean marginal discrepancy values, standard deviations (SD), and multiple comparisons among the fabrication methods are shown in Table 3. 
Table 3. Mean marginal discrepancy values $(\mu \mathrm{m})$ and SD obtained from each fabrication method

\begin{tabular}{cccc}
\hline Fabrication method & Mean (SD) & Minimum & Maximum \\
\hline HM & $57(4)^{\mathrm{a}}$ & 52 & 68 \\
SM & $69(7)^{\mathrm{b}}$ & 58 & 80 \\
L25 & $58(6)^{\mathrm{a}}$ & 50 & 73 \\
L50 & $65(7)^{\mathrm{b}}$ & 55 & 85 \\
\hline
\end{tabular}

*Values having same letter are not significantly different $(P>.05)$.

\section{DISCUSSION}

The main objective of this in vitro study was to evaluate the effects of sintering processes on marginal discrepancy in the sites facing the pontic. The results of the present study showed no significant marginal discrepancy differences among the axial sites in metal frameworks fabricated using three different sintering-based CAD/CAM methods. Therefore, the hypothesis that the amount of marginal discrepancy would increase in the sites facing the pontic of metal frameworks fabricated using sintering-based CAD/CAM methods was rejected.

The pontic part of a metal-ceramic restoration contains much more metal and ceramic mass than the other parts of the restoration. The hypothesis of the present study was based on the idea that thermal contraction after the cooling process in the sites facing the pontic might be greater than in other axial sites, and the amount of marginal discrepancy in the sites facing the pontic would increase. Controversial results were observed in the present study. Wettstein et al. ${ }^{26}$ evaluated the internal gaps of zirconia and metal frameworks for fixed partial dentures and found that metal frameworks exhibited significantly lower discrepancy values in the sites facing away from the pontics than sites facing the pontics. However, they used a conventional casting method. The methodology of the present study was based on sintering-based CAD/CAM techniques. Sintering and casting processes both involve thermal manufacturing stages, but they are completely different from each other, especially in terms of the cooling mechanism.

Komine et al. ${ }^{28}$ compared anterior curved and straight four-unit zirconia frameworks in terms of marginal discrepancy and reported that the straight design exhibited significantly better marginal discrepancy than the curved design. In the present study, only posterior straight design metal frameworks were evaluated, and this design was limited to only one pontic area. The increase in the pontic number and the degree of the curve might lead to different results.

In the available literature, a common consensus exists that marginal discrepancy values higher than $120 \mu \mathrm{m}$ are not clinically acceptable. ${ }^{3,5,29-32}$ In the present study, no metal framework exhibited a mean marginal discrepancy value higher than $70 \mu \mathrm{m}$. Moreover, it was reported that marginal discrepancy values lower than $80 \mu \mathrm{m}$ could not be clinically observable. ${ }^{32}$ Therefore, all fabrication methods were found to be clinically successful in terms of marginal adaptation.

In the present study, a significant marginal discrepancy difference $(P<.001)$ was found among the fabrication methods. The metal frameworks fabricated via the hard milling method exhibited significantly lower marginal discrepancy values than those fabricated via the soft metal milling method. Paşalı et al..$^{33}$ and Vojdani et al. ${ }^{34}$ found similar results. However, Park et al..$^{24}$ compared the adaptation of metal frameworks fabricated using hard metal milling and soft metal milling methods and found that the hard metal milling group exhibited significantly higher cervical and absolute marginal discrepancy measurements than the soft metal milling group. They also concluded that both hard metal milling and soft metal milling methods showed clinically acceptable results $(<120 \mu \mathrm{m})$. Kim et al. ${ }^{22} \mathrm{com}-$ pared the adaptation of metal frameworks fabricated using conventional casting, hard metal milling, laser sintering, and soft metal milling methods and found that the soft metal milling group exhibited significantly lower marginal discrepancy values than the other groups. Pre-sintered soft metal frameworks are sintered until they reach full density after the milling process is completed, which is similar to pre-sintered zirconia restorations. This sintering process results in a contraction in the metal framework by approximately 10 $11 \%$, and the metal framework reaches its final dimensions and hardness. ${ }^{22-25}$ The sintering process requires a sensitive, high-level technique. The contraction mechanism of presintered soft metals can potentially lead to smaller accuracy differences than hard metals.

Moreover, the metal frameworks fabricated using 25 $\mu \mathrm{m}$-laser sintering methods exhibited significantly lower marginal discrepancy values than metal frameworks fabricated by $50 \mu \mathrm{m}$-laser sintering methods in the present study. In contrast to this finding, no significant marginal discrepancy differences were found between $25 \mu \mathrm{m}$-laser sintered and 50 $\mu \mathrm{m}$-laser sintered single unit metal frameworks in a previous study. ${ }^{35}$ Several researchers have noted that increasing the sintering layer's thickness has a negative effect on the accuracy of the final structure. ${ }^{10,14-19}$ One of the most important reasons for this finding is that the laser's penetrative power decreases as the layer thickness increases, and therefore, a balling effect occurs within the structure. A balling effect can be defined as a kind of porosity that causes poor interlayer bonding between the fresh layer and the previously sintered layer, ${ }^{36}$ which may explain the present results. Furthermore, the present study evaluated three-unit metal frameworks rather than single-unit metal copings, and the metal framework's size may affect marginal accuracy.

In the present study, three-unit straight metal frameworks were evaluated. Different metal framework designs may exhibit different results. Moreover, the metal frameworks were not veneered with ceramic material, so a secondary marginal discrepancy evaluation was not conducted. A previous study reported that marginal discrepancies 
increased after ceramic firing. ${ }^{7}$ Although the significant differences were found among the fabrication methods, all of them exhibited clinically acceptable marginal discrepancy results, and this statistical difference may not be clinically relevant.

\section{CONCLUSION}

Within the limitations of this study, marginal discrepancies were not significantly increased, and all the fabrication methods exhibited acceptable marginal accuracy. Decreased layer thickness may provide more favorable marginal discrepancy result in laser-sintered metal frameworks. Although the soft metal milling systems provide important advantages in terms of duration of the milling process and wear of milling equipment, hard metal milling may provide more accurate adaptation in metal frameworks.

\section{ORCID}

Necati Kaleli https://orcid.org/0000-0001-9176-5356

Çağr1 Ural https://orcid.org/0000-0001-5613-2027

Yeşim Ölçer Us bttps://orcid.org/0000-0003-4917-4899

\section{REFERENCES}

1. Roberts HW, Berzins DW, Moore BK, Charlton DG. Metalceramic alloys in dentistry: a review. J Prosthodont 2009;18:18894.

2. Willer J, Rossbach A, Weber HP. Computer-assisted milling of dental restorations using a new CAD/CAM data acquisition system. J Prosthet Dent 1998;80:346-53.

3. Bindl A, Mörmann WH. Marginal and internal fit of all-ceramic CAD/CAM crown-copings on chamfer preparations. J Oral Rehabil 2005;32:441-7.

4. Kokubo Y, Tsumita M, Kano T, Sakurai S, Fukushima S. Clinical marginal and internal gaps of zirconia all-ceramic crowns. J Prosthodont Res 2011;55:40-3.

5. Yeo IS, Yang JH, Lee JB. In vitro marginal fit of three all-ceramic crown systems. J Prosthet Dent 2003;90:459-64.

6. Strub JR, Rekow ED, Witkowski S. Computer-aided design and fabrication of dental restorations: current systems and future possibilities. J Am Dent Assoc 2006;137:1289-96.

7. Kaleli N, Saraç D. Influence of porcelain firing and cementation on the marginal adaptation of metal-ceramic restorations prepared by different methods. J Prosthet Dent 2017;117: 656-61.

8. van Noort R. The future of dental devices is digital. Dent Mater 2012;28:3-12.

9. Örtorp A, Jönsson D, Mouhsen A, Vult von Steyern P. The fit of cobalt-chromium three-unit fixed dental prostheses fabricated with four different techniques: a comparative in vitro study. Dent Mater 2011;27:356-63.

10. Ekren O, Ozkomur A, Ucar Y. Effect of layered manufacturing techniques, alloy powders, and layer thickness on metalceramic bond strength. J Prosthet Dent 2018;119:481-7.

11. Santos EC, Shiomi M, Osakada K, Laoui T. Rapid manufac- turing of metal components by laser forming. Int J Mach Tools Manufact 2006;46:1459-68.

12. Koutsoukis T, Zinelis S, Eliades G, Al-Wazzan K, Rifaiy MA, Al Jabbari YS. Selective laser melting technique of $\mathrm{Co}-\mathrm{Cr}$ dental alloys: A review of structure and properties and comparative analysis with other available techniques. J Prosthodont 2015;24:303-12.

13. Mazzoli A. Selective laser sintering in biomedical engineering. Med Biol Eng Comput 2013;51:245-56.

14. Bae EJ, Kim JH, Kim WC, Kim HY. Bond and fracture strength of metal-ceramic restorations formed by selective laser sintering. J Adv Prosthodont 2014;6:266-71.

15. Chockalingam K, Jawahar N, Chandrasekhar U. Influence of layer thickness on mechanical properties in stereolithography. Rapid Prototyping J 2006;12:106-13.

16. Mercelis P, Kruth JP. Residual stresses in selective laser sintering and selective laser melting. Rapid Prototyping J 2006;12: 254-65.

17. Sames WJ, List F, Pannala S, Dehoff RR, Babu SS. The metallurgy and processing science of metal additive manufacturing. Int Mater Rev 2016;61:315-60.

18. Schaub DA, Chu KR, Montgomery DC. Optimizing stereolithography throughput. J Manuf Syst 1997;16:290-303.

19. Withers PJ, Bhadeshia H. Residual stress Part II - nature and origins. Mater Sci Technol 2001;17:366-75.

20. Tara MA, Eschbach S, Bohlsen F, Kern M. Clinical outcome of metal-ceramic crowns fabricated with laser-sintering technology. Int J Prosthodont 2011;24:46-8.

21. Sun J, Zhang FQ. The application of rapid prototyping in prosthodontics. J Prosthodont 2012;21:641-4.

22. Kim EH, Lee DH, Kwon SM, Kwon TY. A microcomputed tomography evaluation of the marginal fit of cobalt-chromium alloy copings fabricated by new manufacturing techniques and alloy systems. J Prosthet Dent 2017;117:393-9.

23. Lambert H, Durand JC, Jacquot B, Fages M. Dental biomaterials for chairside CAD/CAM: State of the art. J Adv Prosthodont 2017;9:486-95.

24. Park JK, Kim HY, Kim WC, Kim JH. Evaluation of the fit of metal ceramic restorations fabricated with a pre-sintered soft alloy. J Prosthet Dent 2016;116:909-15.

25. Stawarczyk B, Eichberger M, Hoffmann R, Noack F, Schweiger J, Edelhoff D, Beuer F. A novel CAD/CAM base metal compared to conventional CoCrMo alloys: an in-vitro study of the long-term metal-ceramic bond strength. Oral Health Dent Manag 2014;13:446-52.

26. Wettstein F, Sailer I, Roos M, Hämmerle CH. Clinical study of the internal gaps of zirconia and metal frameworks for fixed partial dentures. Eur J Oral Sci 2008;116:272-9.

27. Büchi DL, Ebler S, Hämmerle CH, Sailer I. Marginal and internal fit of curved anterior CAD/CAM-milled zirconia fixed dental prostheses: an in-vitro study. Quintessence Int 2014; 45:837-46.

28. Komine F, Gerds T, Witkowski S, Strub JR. Influence of framework configuration on the marginal adaptation of zirconium dioxide ceramic anterior four-unit frameworks. Acta Odontol Scand 2005;63:361-6.

29. Conrad HJ, Seong WJ, Pesun IJ. Current ceramic materials 
and systems with clinical recommendations: a systematic review. J Prosthet Dent 2007;98:389-404.

30. Kocaağaoğlu H, Kilınç Hİ, Albayrak H, Kara M. In vitro evaluation of marginal, axial, and occlusal discrepancies in metal ceramic restorations produced with new technologies. J Prosthet Dent 2016;116:368-74.

31. Sulaiman F, Chai J, Jameson LM, Wozniak WT. A comparison of the marginal fit of In-Ceram, IPS Empress, and Procera crowns. Int J Prosthodont 1997;10:478-84.

32. McLean JW, von Fraunhofer JA. The estimation of cement film thickness by an in vivo technique. Br Dent J 1971;131: 107-11.

33. Pasali B, Sarac D, Kaleli N, Sarac YS. Evaluation of marginal fit of single implant-supported metal-ceramic crowns prepared by using presintered metal blocks. J Prosthet Dent 2018;119:257-62.

34. Vojdani M, Torabi K, Atashkar B, Heidari H, Torabi Ardakani M. A comparison of the marginal and internal fit of cobaltchromium copings fabricated by two different CAD/CAM systems (CAD/ milling, CAD/ Ceramill Sintron). J Dent (Shiraz) 2016;17:301-8.

35. Kaleli N, Ural Ç, Özköylü G, Duran İ. Effect of layer thickness on the marginal and internal adaptation of laser-sintered metal frameworks. J Prosthet Dent 2019;121:922-8.

36. Gu D, Shen Y. Balling phenomena in direct laser sintering of stainless steel powder: Metallurgical mechanisms and control methods. Mater Des 2009;30:2903-10. 